Filología y Lingüistica XI (1): 15-28, 1985

\title{
ALFONSO X EL SABIO Y EL ROMANCE CASTELLANO
}

Manuel Antonio Quirós R.

\begin{abstract}
This article is written to observe the $700^{\text {th }}$ anniversary of the death of Alfonso $X$ the wise. It refers to the work of Alfonso $X$ in the difussion of "drecho" Spanish, by means of translation into this language from historical, legal and scientific texts in the classic and Arab tradition. The article also summaryes the opinions of certain researchers as to the linguistic and cultural work of Alfonso $X$.
\end{abstract}

\section{introducción: finalidad del presente trabajo}

Eil fin primordial de este análisis es estudiar la winithad de Alfonso X el Sabio (nacido en Toledo 23 de diciembre de 1221) desplegada en pro del lano: un quehacer intelectual encaminado, todo, hacia el buen empleo en la prosa históriuridica y científica. El castellano se constituye unidad lingüística hispana en desmedro, no de los otros dialectos iberorrománicos, sino del mismo latín, no tanto vulgar, pues ya no sino del medieval.

La labor de Alfonso el Sabio es de capital imncia para la fijación e imposición oficial del lano a partir del respectivo dialecto, oriundo sitio determinado y de cierta época, difíciles ecisar.

Mediante este trabajo honramos la imperecedememoria del Rey Sabio con motivo de los 700 de su defunción en Sevilla, el 4 de abril de 34.

Siga su perenne actividad de faro y guía para uienes nos dedicamos, de una forma u otra, al Itivo de la lengua castellana!

El movimiento centrífugo de las lenguas ronces

En la consideración histórica de las relaciones latín con las lenguas romances, el alejamiento éstas a partir del primero constituye una fragntación idiomática: el latín, lengua indoeuropea rentemente unida, se resquebraja en diversidalingüísticas: las lenguas y los dialectos neolatio románicos.
El movimiento centrífugo, que separa y aleja del centro, Roma, es la ruptura de la relativa coherencia interna del latín, sobre todo del vulgar. Este, en determinado momento difícil de precisar, deja de ser latín y se fragmenta en variedades lingüísticas: los dialectos y las lenguas romances. EI nombre genérico de romance o de románico es un derivado del glorioso nombre de ROMA, con la significación de "procedente de Roma" o "a la manera de los romanos"... Se origina una nueva unidad histórica, cultural y lingüistica: la ROMANIA (con naciones como Italia, Francia y España) contrapuesta a la Graecia, Germania, Britannia, y Slavia.

\section{EI movimiento centrípeto de las lenguas ro- mances}

Antítesis del movimiento centrífugo es el centrípeto: un regreso a la otrora perdida unidad idiomática. Este movimiento busca y tiende hacia el centro: el florentino originaría el italiano; el francón, al francés; el castellano al español, etc.

La acción centrípeta hacia el tercero, en desventaja de los restantes dialectos, se inicia con la escritura de textos en romance castellano (siglo XII) y con la creación de obras literarias (siglo XIII). Precedentemente, el romance hispano había sido empleado en glosas, canciones populares, diversiones juglarescas, relatos épicos y en obras didáctico-doctrinales; pero en la prosa científica sólo el latín poseía valor como instrumento creativo. Su estudio, por una élite intelectual, se realizaba en los monasterios. Quedaba la mayor parte del pueblo al 
margen de la educación y de la cultura. Por su parte, la lengua romance no gozaba todavía del privilegio de ser empleada en actas oficiales ni en documentos históricos y legales; imenos en la exposición científica!

\section{IV.Nombre, época y lugar de origen del castellano}

El nombre de "castellano" es un derivado del sustantivo Castilla, procede del latín castella (neutro plural de castellum, 'fortín', 'reducto', 'fortaleza') por ser Castilla, al inicio de la Reconquista, una región fortificada para defensa contra los moros.

La primera documentación del nombre de Castilla, "Territorium Castellae", data del 800.

La variedad latina castellana tuvo origen en un lugar sencillo y humilde, situado en un rincón de la Antigua Cantabria o Vardulia.

Sus primeros habitantes, los castellanos, eran moradores heterogéneos, que emplearían un latín vulgar coloquial y bastante romanceado, propio de vascos y de cántabros semirromanizados. ¿Sería una varidad asturiano-leonesa-visigótica-vascocantábrica? ¿Tendría características propias? Es probable. ¿Era de procedencia galaica y emparentada con el leonés? De seguro poseía estridencias y más rusticidad que el asturiano-leonés y que el visigótico.

La época de origen del castellano, por falta de testimonios escritos, es difícil de precisar: ¿del siglo $\mathrm{VI}$ al $\mathrm{X}$ ?

\section{El Reino Visigético, la Conquista Arabe y la Reconquista Castellana}

Los visigodos pisaron terreno ibérico en el 414, víspera de la Caída del Imperio Romano de Occidente (476). Eran una tribu germánica bastante romanizada. Esta logró vencer la población heredera de la cultura de Roma y amalgamarse con ella, aunque tardíamente.

Durante el Reino Visigótico se formó una cierta unidad hispánica. Su lengua era el romance visigótico: un latín vulgar muy romanceado con préstamos dialectales germánicos. Una vez constituida la unidad política, el reino sucumbe en 711 ante el poder musulmán. La península quedará fragmentada o amalgamada, durante ocho siglos, en dos culturas: la románico-visigótica y la semítica o árabe-judía.

Desaparecido el reino visigótico, se engendran ansias de sus seguidores por reconstruirlo; son los anhelos, sobre todo, de Alfonso I y de Pelaya quienes, desde el lejano septentrión, inician el proceso histórico conocido como la Reconquista. Su máxima aspiración: la corona de Toledo. Por de pronto, deberán contentarse con Asturias, luege con León y después con Castilla; ésta se erige en la abanderada principal, y de conquista en conquista va extiendo, en forma de cuña o de abanico, su dominio militar, político, cultural y lingüístico, de norte a sur.

El castellano ya implantado en Toledo (1085) logra imponerse no sin dificultades y resistencia del latín medieval, pobre, de la época. Este, bajo Alfonso el Sabio, sería sustituido por el castellano.

iHe aquí que se realiza el viejo sueño de la monarquía visigótica! : la reconquista de la capital del reino otrora románico-visigótico. Toledo, ahora bajo la égida de Castilla, se convierte en la nueva cabecera del reino, en donde convivirán cuatro culturas: la románico-germánica, la latino-eclesiástica, la hebrea y la árabe.

Fue pues, por motivo de la Reconquista que el dialecto castellano logra penetrar (hecho fortuito) en Toledo. Los demás dialectos iberorrománicos (se excluyen el gallego-portugués y el catalán), sobre todo los mozárabes, sucumben ante el avance arrollador del castellano.

\section{Llegada e implantación del castellano en la Corte de Toledo}

¿Cómo y por qué llega a Toledo el castellano y se implanta en su corte? El motivo es predominantemente militar: los castellanos, conforme van avanzando de norte a sur con móviles de conquista, logran, en modo indirecto, implantar su forma de hablar. En el siglo IX, se apoderan de los territorios hasta la línea del Arlanzón (Burgos); en el siglo $X$, toman la línea del Duero (Castilla la Vieja es reconquistada); en el siglo $\mathrm{XI}$, el avance se extiende hasta la línea del Tajo (ocupa, consiguientemente, Toledo). -EI reconquistador de ésta es Alfonso VI en 1085. Por el mismo tiempo, Rodrigo Díaz de Vivar ocupa Valencia-; en el siglo XII, bajo Fernando III el Santo, padre de Alfonso $X$, concluye el ímpetu liberador castellano, con Sevilla como último baluarte digno de consideración. Así pues, el ensanchamiento del reino, a costa de los árabes, y la respectiva repoblación en las urbes, actúan como elementos esenciales de la castellanización. 


\section{Marco histórico de Alfonso el Sabio}

El período del reinado de Alfonso $X$ se extienI de 1252 al 4 de abril de 1284, fecha de su

Tineses políticos y familiares inducen a don Alnu alia vez más, a dedicarse de lleno al trabajo

E momarca era hijo de Fernando III el Santo y muriz de Suabia; por tanto, un legítimo aspisalla corona del Imperio Germánico; pero no de seguro que la Iglesia no veía con príncipe católico que se rodeaba de

uaninss ivudíos y musulmanes.

Dineste la perspectiva militar el reinado del Rey sandite está enmarcado en los momentos finales de an Feronquista: pocos años ha, había tenido luand ile framosa Batalla de las Navas de Tolosa, baanilie pue resquebrajó, casi en modo definitivo, el Jnunio árabe en la Península Ibérica. Lo que sizane som simples escaramuzas sureñas, cuyo climax anian reconquista de Granada en 1492.

\section{Marco cultural de Alfonso el Sabio}

Miffonso $\mathrm{X}$ el Sabio, estudioso, más que guerreWis leurado, más que político; hombre de pensaminimtios, más que de acción, constituye un prerrenumiemiento del humanismo; por consiguiente, las merras y las artes tienen cabida en su seno. Su labor, ina the en precursor, es la continuación, en parte, de lia emprendida por la famosa Escuela de Traductones de Toledo. Con él en persona, gran parte de waw reinado sè constituye en un crisol de cultura universal y cosmopolita, en donde el rey mismo es = simbolo de la unidad. Su intensa actividad inteiemeall lo hace un monarca amante de la cultura: um continuador de Carlomagno y preludio de los mrincipes renacentistas, quienes se hacían rodear a personas con intereses poco comunes: músicos, puetas, pintores, científicos, historiadores, traducanres y sabios. Es Alfonso lo que hoy llamaríamos un académico; por eso dedica más el tiempo al multivo del saber; es un hombre de pluma, no de sspada.

La época de Alfonso el Sabio está enmarcada tentro de la cultura del siglo XIII: período de los inicios de las universidades occidentales, de la filosufía escolástica, de los poetas trovadores (con su amor cortés), de la corte literaria de Federico II, precursor del "Dolce Stil Nuevo", de los glosadones jurídicos, de la caballería y de las Cruzadas de
San Luis. Alfonso, un coetáneo de Dante Alighieri, es también un digno representante de la cultura de tal siglo.

En Hispania, dentro de tal marco cultural, se destaca Toledo como centro y punto de unión de varias culturas, según lo manifestado. En ella, desde su reconquista por Alfonso $\mathrm{VI}$, operaba la Escuela de Traductores de Toledo bajo la guía del arzobispo Raimundo (1130-1150).

A través de ésta, entra en Europa el aristotelismo de Averroes, se conocen los libros de Avicenas, pues se estudian y traducen al latín libros en árabe. Además, muchos judíos ilustrados, fugitivos de los almohades, encuentran acogida en tal centro.

\section{Situación del romance prealfonsino.}

Antes de que Alfonso $X$ el Sabio iniciara su reinado, ya se había comenzado a emplear el romance (no necesariamente castellano), verbi gratia, en las Glosas Emilianenses, en las Glosas Silenses, en las jarchas árabe-andaluzas, en el Cantar de mio Cid, en la traducción del "Forum Judicum" (Fuero Juzgo), en las Flores de Filosofía (una colección de máximas), en el "Bononium" o Bocados de oro (unas sentencias político-morales), en el Poridad de Poridades (Secreto de Secretos), en el Libro de los Doce Sabios o de la Nobleza y la Lealtad (en donde, ilustres varones le proporcionan enseñanzas doctrinales a un joven rey sobre la justicia, fidelidad, etc., en la Disputa del cristiano y el judio (primera prosa en vulgar, que discute aspectos de tipo religioso) y en otras más.

A pesar del empleo del romance en las obras anteriores, lo cierto es que por parte de los clérigos persiste el favoritismo hacia el latín, lengua de la doctrina en la Edad Media. Además, muchos consideran el romance una jerga bárbara de gente inculta, digno sólo de la comunicación oral y familiar, pues era trivial e indigno de ser escrito en historia, filosofía, derecho y narrativa, para lo cual estaba el latín de gran tradición literaria y cultural. En confrontación con éste, el romance resultaba pobre y anárquico, según ellos.

Con don Alfonso cambia radicalmente la concepción en torno al romance; es principio de todo saber y ciencia. Y así, inicia su marcha triunfal, no sólo en el empleo como léngua escrita, sino también literaria y oficial del reino. Carlomagno había tratado de restablecer el latín de su tiempo; Alfonso hace lo mismo con el romance castellano. 


\section{$X$. Motivos de la imposición y aceptación del caste- llano como lengua oficial}

Por el simple hecho de ser el medio de la expresión oral del principal pueblo portador de la Reconquista, el castellano traía consigo muchos méritos. Tampoco se debe olvidar que éste ya había sido aceptado como lengua escrita desde Fernando III.

Además, Alfonso $X$ el Sabio, hombre culto, sabía de otros romances que ya habían sido usados como expresión escrita en vez del latín: la magnífica lírica trovadoresca en lengua de oc (los poetas trovadores, sea por desconocimiento o por otros motivos, hacían caso omiso del latín). La lengua de oil era fomentada desde hacía un siglo; incluso, en ella se habían expresado italianos como Marco Polo y Brunetto Latini, maestro de Dante.

Sin duda, lo que más había motivado a nuestro monarca fue el ejemplo mismo de su padre, quien mandó traducir para Córdoba, reconquistada en 1241, el Liber Judicum, bajo el nombre de "Fuero Juzgo", la antigua ley visigótica de Recesvinto: conforme se iba extendiendo la Reconquista hacia el sur peninsular, era normal que comenzaran a aparecer intereses locales en merma del poder real, lo cual no le era de ninguna utilidad política a Fernando III; entonces éste trata de reducir los pequeños intereses locales mediante la imposición de un fuero general en idioma castellano, para que fuese comprendido por todos sus súbditos. Poco importa el latín, ; $\$$ I son cada vez menos quienes lo entienden $y$ estudian! De hecho, en las ciudades reconquistadas, la lengua de Roma no pudo recobrar el prestigio de otrora. Cuando el Forum Judicum se convierte en "Fuero Real", ya el latín no goza de renombre, y un regreso al pasado hubiera sido un retroceso contra los destinos de la historia. Alfonso no titubea ni un solo momento y continúa por el mismo sendero trazado por su padre:

\section{1) El romance en las Siete Partidas}

Alfonso se expresa en romance castellano a la hora de redactar las Siete Partidas, un libro de derecho, para que los súbditos de su reino comprendan y practiquen los consejos expuestos allí.

\section{2) El romance en los libros de historia}

A partir de 1270, la "Primera Crónica General" y la "General Estoria" rompen también con la tradición y desisten del empleo del latín, sin fuerte tradición escolar histórica, pues las obras son p cas: la Historia de rebus Hispaniae de Rodrigo ménez de Rada; el Chronicon Mundi de Lucas Tuy, la Historia Scholastica de Comestor, la Ca tinuatio Hispana o Crónica Mozárabe, la Crónï Albeldense (Emilianense o Vigilana), la Cróni de Alfonso III, la Crónica Silense, el Liber Regun y algún libro más. Por consiguiente, en la esfera di la historia era relativamente fácil romper con tradición de la lengua de Roma.

También desempeña un papel importante, ejemplo del francés con la Estoria françesa Thebas, a saber, le Roman de Thebes (la "fable gesta para Alfonso"); para éste era una obra hist riográfica.

\section{3) El romance en los libros de astronomía}

Aunque la astronomía perteneciera a "Septem artes liberales" de la Edad Media (por tanto, enseñada en latín) Alfonso el Sabio se orientó más bien hacia la astronomía y astrología ára bes, no tradicionales,por lo cual el Rey no emples en este campo el latín. Además, en la elaboración de las obras astronómicas alfonsinas colaboraban judíos, y éstos no ven con simpatía ni agrado el uso del latín, idioma cristiano por excelencia dell dogma y de la liturgia.

\section{4) El romance en los libros de "delectatio"}

En Italia, como en Francia, se empleaba el latín en las obras de aspectos lúdicos; pero tal tradición no fue respetada en "Espanna", pues, desde hacía más de un siglo, muchos cortesanos sólo usaban la lengua románica.

\section{5) El romance y la difusión del saber}

EI Rey Sabio tenía gran interés en que sus súbditos se aprovecharan del bagaje cultural encerrado en los textos, sobre todo árabes... "porque los ommes lo entendiessen meior et se sopiessen dél más aprovechar". Y, a no dudarlo, el monarca consiguió su cometido: la secularización de la cultura mediante la traducción de textos y la difusión del saber científico, para lo cual se hizo rodear de personas dotadas de al tas miras culturales.

Entre tales personas, había hispánicos (cristianos conocedores del latín y del romance) y otras, conocedoras del griego, del árabe y del hebreo. En su "scriptorium" encuentran cabida juglares, músi$\cos$, miniaturistas, historiadores, jurisconsultos, 
\$ $\$$ traductores, con un papel importante man univiersidad alfonsina orientalista, clásica y

\section{Le politica y la lengua}

Minannalle Alvar manifiesta: "En 1276, Alfonso wiane ilim guerra de la Navarrería frente a Felipe el namien de Francia: resultado de la política fue la manzicioin a "nuestro latín": se restituyen las voa finalies a la manera castellana y se deja de unirin se pérdida, que era un galicismo de imporinno cumo es, en buena parte lo debemos a esta wisium alfonsí... La lengua -al volver del fecho del rareria le servía para unos fines de cohesión naannanit: fifente al riesgo de una desintegración movianeste fuera, frente al posible descrédito de lo unian, lla voluntad del Rey es determinar cuál es ince le ha llevado a prestigiar su propia lengua, verwe la lengua, generosamente, le devolverá pres-

\section{Pensamiento alfonsino sobre la lengua}

Eaiste alguna manifestación de política cultuwabre la lengua expresamente formulada por AlX? Al respecto, sólo se cuenta con dos citas ainectas: la primera fue emitida en el prólogo del de la Ochava Esfera; pero de ella sólo se ce la intervención personal del monarca en ura, más bien, de un "español correcto":... willib las razones que entendió eran soueianas et ciladas, et que no eran en Castellano drecho; et las otras que entendió que complian; et quanen el lenguaje endreçolo el por si se" (1). La wnda es transcrita a partir de la GE 1.477 bg:... comi dixiemos nos muchas uezes: el rey faze ibro, non por quel el escriua con sus manos, por que compone las razones del, e las emienet yegua, e enderesça e muestra la manera de o se deuen fazer, e desi escriue las qui el manpero dezimos por esta razon que el rey faze el Otrossi quando dezimos: el rey faze un palaalguna obra, non es dicho por quelo el se con sus manos, mas por quel mando fazer e las cosas que fueron mester por ello; e qui esto ple aquel a nombre que faze la obra"... De esta se deduce cómo la acción del rey fue, más la de un albañil, la de un arquitecto, que crea, y enmienda.

\section{EI castellano “drecho", ¿la norma toledana?}

\section{¿Qué entiende el Rey Sabio bajo el concepto de castellano drecho?}

Este no era la lengua del lugar en donde estaba asentada la corte, Toledo, sino la de Burgos, más pocos aspectos de la primera y del dialecto de León.

Era el romance castellano oriundo de una región mucho más cercana a Burgos que a Toledo; hacia aquí fue transplantado por los ejércitos de Castilla en 1085; una vez arraigado, obtuvo pulimiento y soltura; luego se impuso como lengua oficial del reino después de la promulgación de algunas diposiciones al respecto: en lo tocante a la diferencia semántica de un vocablo, el rey ordenó que "recurriesen con él a la ciudad de Toledo como a metro de la lengua castellana y que pasasen por el entendimiento que al tal vocablo aquí se le diese por tener en ella nuestra lengua más perfección que en otra parte". Toledo se convirtió en el espejo del castellano por el prestigio de su corte, luego de haber aceptado la lengua burgalesa también por mérito del Rey Sabio. Por eso, "a fines del siglo XVI, Burgos difundía sus innovaciones fonéticas, pronunciando hacer en vez de jaser, razón en vez de rasón, y quijada en vez de quisada. Como la cultura había unificado fundamentalmente la semántica o, como decía el Rey Sabio, el entendimiento de los vocablos, el habla de Burgos, con su viejo prestigio, fue el prototipo del habla española, quedando en la categoría de regionalismos de España y de América los tipos de jarina y desir del habla toledana (2).

Para Rafael Lapesa (1948) al castellano drecho es la norma toledana:..." Según tradición cuyo fondo histórico no está comprobado, aunque persistentemente atestiguada siglos más tarde, Alfonso $X$ ordenó que en los usos jurídicos el sentido de las palabras ambiguas o regionales se determinase de acuerdo con el lenguaje de Toledo.

La grafía quedó sólidamente establecida; puede decirse que hasta el siglo XVI la transcripción de los sonidos españoles se atiene a normas fijadas por la cancillería y los escritos alfonsíes" (3).

Sin embargo, anteriormente Galán (1954) opinaba que no existe ningún documento en el que se indique la nacionalización de un determinado modo de expresarse de algún lugar o ciudad: "Para Alfonso, el castellano correcto era aquel que hablan los caballeros cultos de su corte. Era en general la misma fabla del pueblo de Castilla pero enaltecida por el uso que de ella hacían las personas 
educadas. Un pasaje de la Partida segunda ilustra este criterio cortesano del lenguaje. Aunque la lengua que allí se emplea sea la "vulgar", aconseja que no se debe decir 'ante homes buenos, quanto más decirlas ellos mismos, e mayormente el Rey' y agrega: 'daño muy grande viene al Rey e a los otros omes, quando dixieron palabras malas e villanas' (4).

Jiménez de Rada habla de la "palabra palaciana" (5). En la Partida cuarta se marca la distinción entre "hablar paladinamientre" y "hablar corrompudamiembre", aunque "paladinamente" significa lengua de la corte.

Hans-Josef Niederehe; en su libro Die Sprachauffassung Alfons des Weisen (el estudio más serio que consultamos en torno a Alfonso $X$ el Sabio) (6) manifiesta que para Alfonso no existe ninguna norma determinada:... "macht damit deutlich -Alfonso-, dass es für ihn noch keine, in einem bestimmten Sprachsystem gegründete, Norm gibt"... En seguida, este autor nos habla de la exactitud (exact) (7): poco le importa a nuestro monarca una forma étnica y social determinada, sino que el contenido queda plasmado lo más exactamente posible (como se nota, es una concepción orientada más hacia el contenido que a la forma, langue).

Sea como fuere, el castellano drecho de Alfonso $X$, bajo norma toledana o no, sirvió de marco para la manifestación de todo un contenido histórico, legal y científico, lo cual fue bien comprendido por Gil Zamora cuando se expresó del siguiente modo: "Adeo quoque animun suum transtulit ad investigandas et prescrutandas mundanas scientias et divinas, quod omnes fere scripturas quoque theologicas seu divinas transferri fecit in linguam maternam; ita ut omnes possent evidentissime intueri et intelligere quomodo illa, que sub linge latine phaleris et figura tecta et secreta, etiam ipsis sapientibus, videbantur (8).

\section{Denominaciones dadas por Alfonso $X$ el Sa- bio a su lengua materna}

Nuestro monarca designa su vulgar materno, el castellano, con diversos nombres:

\section{1) Lenguaje}

"Nuestro lenguaje"; "en el lenguaje". Con este nombre seguido de Castilla o de Espanna: "en el nuestro lenguaje de Castilla"; "en el lenguaje de Castilla", un uso muy común. "Llamamos en lenguaje de Espanna. Cita: (..."fizo el huerto a que todos llaman en el latín suspenssile. Et suspenssile en el lenguaje de Castiella quiere dezir tanto como colgado o colgadizo" (GE 4. fol, 48b-) (9).

\section{2) Lengua}

"En nuestra lengua". O seguida de Castilla: " la nuestra lengua de Castiella", (Cuando el Rey S bio hace referencia a su lengua, no lo hace en tone chovinista, como ciertos teóricos franceses del ro nacimiento, sino en manera simple y sencilla, $n$ bien, en una actitud de diferenciación de otra le gua:... "este nombre Sigeo, que muestra tanto $c_{0}$ mo sigith en la lengua de Grecia, e sigith en la de Castiella tanto como chith o callat". CGE 1.634 13-).

\section{3) Castellano}

Consciente de la gama dialectal hispánica, hace uso del término de castellano para diferenciar se habla de las otras peninsulares: "segund el castella no".

\section{4) Romanz de Castilla}

Aquí, sabedor de la procedencia etimológica, usa "romanz", un derivado de romanice: "en el nuestro romanz de Castiella"; "segund el propio romanz castellano"; "en nuestro romance". Pero también emplea esta palabra para la lengua popular de Francia: "Vos me samblez François au parlar lo roman...cis livres est escris en roumanç, selonc la raison de France" (10).

\section{5) Romance como sinónimo de lenguaje:}

Romance como sinónimo de lenguaje está empleado en este ejemplo: "E dizen le (Scil. Postumo) asi en el latín, mas pero asi lo llamamos en el lenguaje, ca non ay otro romançe" (GE 2.1.229 a2).

\section{6) Espannol}

"Dezimos en esta tierra en espannol"; si no es que simplemente emplea "dezimos".

\section{7) Lenguaie de Espanna}

Este es un sinónimo del anterior.

\section{8) Ladino}

Esta denominación, derivada de latino, aparece una sola vez (PART. I 6,4).

\section{9) Conclusión parcial}

Para Alfonso $X$ el Sabio, el romance es la lengua en oposición al latín; por eso, cuando quiere decir 
a reme de Castilla lo precisa con "en el nuestro ranmanr te Castiella".

\section{Acritud de Alfonso el Sabio ante el latín y allewnos romances}

Eremos la opinión de que nuestro monarca vameria minguna actitud chovinista: Alfonso, esinumiversal: además del latín y del castellano, unnawie oteros romances:

\section{III) E latin}

5 muestro rey hace empleo del romance casteanme, es porque considera anacrónico el uso de la - la cultura de su tiempo, sabe que el latín * munado por la mayoría de sus súbditos. Con wnim, auando sea necesario escribir en él, lo hace: - ninioún de alguna carta a una persona que lo o de un documento que no debería ir men su "romanz", pues es necesario que salga ative confines de sus tierras: "mensageros del rey iumuss homes van algunas veces á otras partes fue= sus regnos, et han messter cartas de como wim guiados: et estas deben seer fechas en latin murue las entienden los homes de las otras tierras PसATI. III 18,25). También a un chanciller se le mine "que sepa leer et escrebir también en latín ando en romance" (PART. II, 9,4). Va el escrito Him gitbo a gentes de su jurisdicción territorial, enturnuses el latín no es tenido en cuenta.

En todo caso, la posición de Alfonso X el Sabio In la lengua del Lacio es de aprecio; aun más: se pucoupa de la degradación a que ha llegado en su tames

Conviene manifestar que cuando aparece en la Estoria la expresión "nuestro latín" se trathe una fórmula introductoria de una voz latina; min atros casos pareciera tratarse de un sinónimo Intrellano).

\section{2) El provenzal}

ZConocía nuestro rey-poeta la lengua en que puretizaron los trovadores del sur de Francia, la "ing romana" del "fins amor" (amor cortés)? 7i17. La respuesta es difícil. Sólo parece que redacis una "Declaration que. I senher reis n'Anfos de Costela fe per la suplicatio que Guirautz Riquier E poer lo nom de joglar l'an MCCLXXV" (12). 4ilguien se pregunta si Alfonso no haya usado un "Juative speaker") (13).

\section{3) El galaico}

EI monarca legó la mayor parte de su producción lírica en galaico y no en castellano. ¿Por qué? La respuesta es proporcionada por algunos críticos: condiciones económicas y simpatía por ella (Entwistle). El galaico sería una máscara protectora en donde esconder sus inhibiciones y tabúes; un ventilador para esconder sus sentimientos y emociones no siempre muy castos (A. Castro). Hilty habla de la tradición poética, más fuerte que todas- las demás tendencias lingüísticas. iPero Alfonso pudo haber recurrido al latín! ipor qué no lo hizo? Desde los trovadores provenzales ya no se usaba más el latín en la poesía amorosa; además, ¿no sería comprometedor para un rey católico tratar temas un poco obscenos en el idioma de la Iglesia? ... ¿Seguiría el ejemplo de un Guillermo IX de Poitiers, primer poeta trovadoresco conocido?

XV EI romance en la obra alfonsina; ejemplificaciones lingüísticas

\section{1) Breve introducción}

La producción alfonsina representa, más que nada, un esfuerzo por expresar, en una lengua nueva, temas culturales (históricos, jurídicos y científicos) que sólo habían sido manifestados en lenguas con mayor tradición y capacidad narrativa, como el latín y el árabe. Alfonso se vio obligado a iniciar todo un trabajo concienzudo para colocar su romance en un nivel muy parecido al de estas dos lenguas.

\section{2) Definiciones etimológicas}

A pártir de la etimología de la respectiva palabra, Alfonso externa aspectos que le parecen dignos de aclarar:

"Judio es dicho aquel que cree, e tiene, la Ley de Moysen, segun suena la letra della; e que se circuncida, e faze las otras cosas que manda su ley"...

"Amicitia en latin tanto quiere dexir en romance como amistad; e amistad segund dize Aristoteles, es una virtud que es buena en si, e provechosa a la vida de los omes; e ha lugar propiamente, quando aquel que ama, es amado del otro a quien ama".

"Particion tanto quiere decir como dar a cada uno su derecho de las cosas que se parte"...

"Agiógrafo que quiere dezir tanto commo escritura de Dios". 
No obstante sus preocupaciones por la etimología, Alfonso el Sabio incurre muchas veces, "a la Isidoro de Sevilla", en una manera fantasiosa de etimologizar (la etimología seguirá sin exactitud hasta el siglo XIX). Por ejemplo, en la Crónica General se encuentra tal manera de proceder cuando se trata de dar el origen del nombre de Francia:

"Francia la antigua fue otrossi una partida de Alemanna, e por essol pusieron nombre Francia que quiere dezir tanto como tierra que fue partida en frannida d'Alemanna".

"Este nombre Francia le fue dado de frangere que dizen en latín por franner o crebantar". "Franco, dezimos en el lenguaje de Castiella por quebrantadura y partida" El error de Alfonso el Sabio consiste en derivar la etimología del nombre de Francia del verbo frangere, 'romper', 'quebrar', y no del pueblo germánico de los francos.

\section{3) Glosas por definición}

El constante esfuerzo del rey por hallar la explicación exacta de un vocablo lo lleva a externar, a modo de glosas, cierto tipo de definiciones:

"Oráculo es palabra de latín, e quiere dezir en el lenguaje de Castiella tanto como oradero".

"Las Euménides o furias son las endicheras 'plañideras' dell infierno, a que llaman los gentiles deessas raviosas porque fazen los coraçones de los homnes reviar de duelo".

"Fizieron los príncipes de Roma un corral grand redondo a que llamaban en latín teatro".

"Dicen en latín tribus por linaje".

"Tanto quiere seer dictador cuemo mandador, et dictadura tanto cuemo mandado".

"Tirano tanto quiere dezir como señor cruel, que es apoderado en algún regno o tierra por fuerça o por engaño, o por traición".

"Maestrescuela tanto quiere decir como maestro et proveedor de las escuelas"... Et á esta mesma dignidat llaman en algunos lugares chanceller".

En los ejemplos anteriores, notamos cómo don Alfonso toma una palabra latina y la glosa con un sinónimo, término conocido de su romance casteIlano.

Así procede con términos del árabe: "Dízenles (a unas estellas) en arábigo alqueder, que quiere dezir la olla".

A veces explica, conjuntamente, términos del griego y del hebreo:... "esse mes, a que llaman los griegos xantico e los ebreos nisan; e es este el mes aque nos los latinos dezimos mayo".

\section{4) Sintaxis}

La frase alfonsina es flexible, amplia y variada; por eso, con riqueza de matices: "et amistad de natura es la que ha el padre et la madre a sus fijos, et el marido a la mugier; et este non tan solamiente la han los homes".

\section{5) Morfología}

Los siguientes rasgos aparecen en la esfera morfológica:

- Se incrementa la interposición de palabras entre el pronombre y el verbo: "que me non den"; se de mi partio"; "que me tu diziés".

Vacilación entre el perfecto simple (quiso, vino) y el compuesto (ha querido, ha venido).

- Terminación -ié del imperfecto de indicativo: habié, tenié.

- Mucho uso de la síncopa en el futuro: recibrá, vivré, comré.

- Empleo de perfectos fuertes: apriso (aprendió) fuxo (huyó), tauxo (tañó).

- Concordancia del participio, en número y género, con el complemento directo: tenía una case comprada (había comprado una casa).

- Participios de la segunda conjugación en - udo, no en -ido: sabudo, tenudo, vencudo.

\section{6) Fonética}

iHe aquí algunas características fonéticas de romance alfonsí! :

- Apócope de la /-e/: adux (aduxe), pued (pue de), trist (triste). Ante todo, el apócope tiene lugar en los pronombres enclíticos: dime (dime), tomét (te tomé), quet la dará (que te la dará), quem lo faze (que me lo hace).

Conforme se va avanzando en el tiempo, fijeza y regularidad idiomáticas adquieren ma yor sesgo, se encuentra monte, prise; $\mathrm{m}$ - es sustituida por $m e, \mathrm{~s}$ - por se y $\mathrm{t}$-por te lo cual es una buena muestra del trabajo de corrección emprendido por don Alfonso.

- Uso de la /f-/ en vez de /h-/: fermosura, en lugar de hermosura, forma ésta más reciente y oriunda de Burgos y de su comarca.

- Empleo del sufijo -iello en vez de -illo: Castiella por Castilla. Ambas, la /f-/ e -illo, aparecen por descuido, y aún perviven, en la lengua castellana.

Los sonidos, en su transcripción escrita, van a seguir las normas fijadas por la cancillería alfonsí y por sus escritos, y no sólo desaparecerán muchos 
del precedente dialecto mozárabe, sino que whe va a naufragar en el olvido al ser suplantado por el nuevo idioma, el castellano.

\section{7) Léxico}

A pesar de algunas voces arcaicas, el castellano alfonsino aparece ya como moderno. Por ejemplo, Iegín un autor, el capítulo XIV de la General Esanria posee unos 900 vocablos, 30 de los cuales mecesitan ser glosados.

\section{-Voces populares:}

La mayor parte del vocabulario alfonsino está anstituido por palabras procedentes, en vía direcIan, del latín vulgar o popular, así: tolló, razones, thobladas, drecho, otras, muchas, rey, manera, finter, obra, cosas, mester, nombre, etc.; es que las ubras de Alfonso $X$, aunque parezcan eruditas en all fondo, están basadas en la lengua viva del puethio.

\section{-Cultismos y neologismos:}

El caudal idiomático se puede aumentar mefliante la creación de voces cultas y de neologismos. Dada la gran variedad de fuentes y el carácter enciclopédico de la obra alfonsina, hubo muchas palabras que ingresaron en el romance castellano por tales procedimientos, para lo cual Alfonso el Sabio tenía a portada de mano el latín: cuando al mey le resulta harto difícil inventar una palabra de cosecha romance, recurre al latín e incorpora un altismo o un neologismo: deidat, diversificar, equinoctial, horizón, húmido, septentrión, teatro, etc. Por mérito de nuestro monarca, muchos cultismos actuales proceden del período alfonsí.

\section{-Derivados del mismo castellano:}

El romance aun nuevo de Alfonso $X$ el Sabio, posee varios sustantivos procedentes de otra forma romance, así: ladeza (anchura, latitud), longueza llongitud), asmanza (opinión, creencia), añadimiento (aumento) paladinar (publicar), derivados respectivamente de lado, longo, asmar (creer), añader (añadir) y paladino. La palabra piedra ofrece los siguientes derivados: pedrada, pedrai, pedragoso, pedrenal, pedranno,. pedrere, pedrisco y pe-
dirizo.

\section{-Voces sinónimas:}

El monarca hace empleo de voces sinónimas, una prueba de su riqueza lexical; entre ellas se encuentran: aborrencia, aborrecimiento, aborrimien- to; acrescentador, acrescentudo, acrescudo; batallador, batallant, batalloso; defensión, defendimiento; egualdat, egualenza, eguança; ferradura, ferramienta, ferreria; redondeza, redondura; sensitivo, sentidizo, sentidor; tempradura, tempramiento, tenprança; uileza, uiltanza, etc.

\section{-Alfonso, creador de topónimos:}

En tiempos de don Alfonso X el Sabio prácticamente está conquistado casi todo el territorio hispano, lo cual induce al monarca a sustituir un nombre árabe por el correspondiente románico:

...la Torre que dizien en tiempo de moros de Abenzohar a que puso el Rey don Alfonso nombre Segouiola...

...al Aldea que auie nombre en tiempo de Moros Villalua aquien yo pus nombre Gironda... ...el Aldea que auie nombre en tiempo de Moros Caxar con el barrio que se tiene con ella quel dizen Moriana a que yo pus nombre Torquemada..." (14).

\section{- Voces del árabe en el romance alfonsi:}

También la influencia extranjera se encuentra patente en el léxico alfonsi; de modo que en su lengua no sólo está presente el latín, idioma madre del castellano, sino, además, numerosos préstamos extranjeros: italianos, franceses, occitanos, catalanes, aragoneses, leoneses, germanos, y ante todo, árabes. He aquí algunas voces procedentes del árabe: "Almocadenes llaman agora a los que antiguamente solian llamar cabdiellos de las peonadas" (Partidas). "E en las dos casas al lado destas, están otros dos trebeios que se semeian, e llaman los alfiles en algarabía, que quiere tanto dezir en nuestro lenguaie como elefantes que solien los reyes levar en las batallas". "Alfaqueques tanto quiere decir en arábigo como homes de buena verdat que son puestas para sacar los cativos" (15).

\section{-Conjunciones y locuciones conjuntivas:}

El romance alfonsí no escasea en el empleo de diferentes tipos de partículas invariables, sobre todo, de conjunciones y de locuciones conjuntivas: porque, otrosí, pues que, de quisa, maguer que, como quier, para que, siguiera, aunque, etc.

Particularmente exagerados son los usos de que (lo cual es llamado en el presente queísmo) y del latinismo et ' $y$ '. Ejemplo del primero: "Dixo el rey Salomón... que el que hobiesse sabor de facer bien, que se acompañase con los buenos". (Al presente escribiríamos así: dijo el rey Salomón que quien 
tenga deseos de hacer el bien, debe buscar la compañía de lo buenos).

\section{8) Breve conclusión}

Hacia 1270 , se nota gran disminución en las vacilaciones lingüísticas y en el polimorfismo del castellano empleado por el monarca sabio, pues ya la lengua adquiere más unificación, $y$, en modo particular, la sintaxis se vuelve lógica y coherente.

\section{9) Rápido anexo sobre la gramática según Alfonso X el Sabio}

No es mi propósito hacer ni presentar disquisiciones teóricas sobre la concepción lingüística y gramática exteriorizada por nuestro monarca. Sólo me limito a ofrecer estas dos definiciones de gramática según Alfonso el Sabio:

a) "Llamaron a la una gramática que quiere dezir commo arte que muestra ffablar e escriuir derechamientre, e ffázese con siete cosas:

convo- con con con con con con
luntad boz letra sillaua parte dicho razón

Ca la voluntad enbía la boz; e la boz enbía la letra; la letra, la ssílaba; et la ssílaba, la parte; e la parte, el dicho; e el dicho, la razón. Et assí ssalen vnas de otras e sse aydan" (Set. 29,28).

"La gramatica, que dixiemos que era primer, ensenna fazer las letras, e ayuntar dellas las palabras cada una como conuiene, e faze dellas razón, e por esso le dixieron gramatica que quiere dezir tanto como saber de letras, ca esta es ell arte que ensenna acabar razon por letras e por sillabas et por palabras ayuntadas que se compone la razón". (GE 1. 194a4).

"En el triuio son estos tres saberes: la gramatica que a ell offiçio de fazer las letras et componer ende las partes et ayuntar los latines; la dialectica". (GE 2, 157 a 4). (16).

b) ..."gramática, que es arte pora aprender el lenguage del latín"...

La primera definición había sido formulada en latín por Isidoro de Sevilla, así: "Grammatica est scientia recte loquendi, et origio et fundamentum liberalium artium". (Etym. IV, Isqq.) (17).

\section{Alfonso el Sabio, estilista en romance caste- llano}

Uno de los grandes méritos de la labor alfonsina es el esfuerzo por expresarse con exactitud en el naciente romance, fruto de lo cual fueron la propiedad de los vocablos, a pesar de forjar un léxico nuevo y abundante, la sencillez y flexibilidad de las expresiones, a veces populares y juglarescas, provistas de fluidez y rotundidad. Por eso la prosa alfonsí es ágil y proporciona eficacia didáctica. Los vocablos y expresiones, formas latinas y árabes sirven para plasmar todas las realidades de la esfera humana y científica del monarca sabio.

En su prosa, estaba presente el "moderno corrector de estilo": escribía él mismo o hacía escribir con sentido de lima y pulimiento del instrumento lingüístico; por eso aclaraba lo oscuro. No obstante la multitud de fuentes y la gran cantidad de personas (de diversa procedencia) que colaboraban en el scriptorium del Rey Sabio, el ingente esfuerzo hizo a la prosa apta para la expresión unitaria con estricta fidelidad al original.

Fue Alfonso $X$ el Sabio el gran inspirador $y$ motivador de su círculo de estudios; aunque no siempre el creador directo, sí la mente suprema; su labor fue, más que de albañil o carpintero, la de un arquitecto.

La prosa alfonsina, por tener ausencia de tono personal, no manifiesta grandes intereses estéticos, pues su castellano tenía sólo una finalidad: lo didáctico y lo científico, de donde su estilo seco y a veces hasta tosco. Sin embargo, no faltan páginas dotadas de belleza, como cuando se expresan, en la General Estoria los Llantos de Jeremías. También es elocuente en belleza el famoso "Elogio de España" de la Crónica General dados su animación y entusiasmo lírico: "Esta Espanna que dezimos tal es como el Paraíso de Dios, ca riégase con cinco ríos caudales, e cada uno dellos tiene entre sí et ell otro grandes montannas e tierras; et los ualles et los Ilanos son grandes et anchos, et por la bondad de la tierra et ell humor de ríos lievan fructos et son abondados. Espanna la mayor parte della se riega de arroyos e de fuentes et nunqual minguan poços cada logar o los a mester. Espanna es abondada de miesses, deleytosa de fructas, viciosa de pescados, sobrosa de leche et de todas las cosas que se della fazen; lana de uenados, et de caça, cubierta de ganados, loçana de cavallos, prouechosa de mulos, segura et bastida de castiellos, alegre por buenos uinos, ffolgada de abondamiento de pan; rica de metales de plomo, de estanno, de argent uiuo, de fierro, de arambre, de plata, de oro, de piedras preciosas, de toda manera de piedra mármol, de sales de mar, et de salinas de tierra"...(18). 


\section{KVII.Pasos en la corrección de estilo}

Referente a la labor final de la corrección del Iexto escrito, el Rey Sabio emprendía varios pasos: luego de haber fijado el plan laboral, de deciLiir las fuentes dignas de empleo, de seleccionar a sus colaboradores (ayuntadores y trasladores), emprendía la corrección estilística en sí:

1) Proporciona aclaraciones mediante etimología, definiciones y glosas.

2) Elimina la anarquía lingüística y la rigidez sintáctica.

3) Crea o amplía el léxico.

4) Les da a los vocablos su sentido propio.

5) Corrige la gramática. En síntesis, su labor estilística consistía en "endreçar el lenguaje", para obtener un castellano drecho, eliminando lo eliminable con la finalidad de obtener un todo orgánico, pues el castellano tenía que ser el instrumento expresivo en favor de aquellas disciplinas que estaban a punto de ser difundidas desde su "scriptorium".

\section{EI arte de la traducción al romance alfon- sino}

\section{1) Breve introducción}

La traducción de textos clásicos y orientales, ante todo árabes, representa un papel primordial en el "scriptorium alfonsí". En esta esfera, se continúa la obra emprendida por la Escuela de Traductores de Toledo, un crisol de varias culturas.

Para que los respectivos textos sean estudiados y comprendidos, se realiza un encomiable trabajo en equipo de traducción. Aquí también está presente la mente guía, don Alfonso, quien, además de elegir las fuentes y de decidir el objeto digno de traducción, acepta o rechaza a los traductores (trasladores). Una vez que éstos habían obtenido el cometido, eran seguidos por los "ayuntadores", después por los "enmendadores", luego por los coordinadores de los pasajes encontrados en las mismas fuentes; seguía la redacción en sí, la cual perseguía, ante todo, un texto unitario. La división en capítulos era realizada por los "capituladores", quienes también se encargaban de la rotulación. Finalmente, ihe aquí al Rey presente! : pone orden en las partes que lo ameritan, pues le desagradan, y le da una última enmienda al castellano ya revisado por los "enmendadores".

\section{2) Frutos de la labor de traducción}

Las traducciones en romance castellano abarcan varias disciplinas: filosofía, literatura, historia, música, matemáticas, astronomía, medicina, etc. Las siguientes obras proceden de Alfonso $X$ el Sabio $y$ de su equipo de traductores: Calila e Dimna (una colección de apólogos orientales); el Septenarium, especie de disciplina científica según el "Trivium" y el "Quadrivium"; Libros del saber de astronomía y las Tablas alfonsíes, ambas, traducciones y adaptaciones de libros orientales; Libro de los juegos de ajedrez, dados y tablas, directamente del árabe.

Con referencia al trabajo de don Alfonso en la esfera de la traducción, su sobrino, don Juan Manuel, manifiesta lo siguiente: "Fizo trasladar en este lenguaje de Castilla todas las ciencias..., toda la secta de los moros porque paresciese por ella los errores en que Mahomad, el su falso profeta, les puso...; otrosí fizo trasladar toda ley de los judíos e aun el Talmud. E otra ciencia que han los judios muy escondida a que llaman Cabala. E esto fizo porque paresce manifiestamente por la su ley que los cristianos habemos...otrosí romanzó todos los derechos eclesiásticos e seglares"...

\section{Legado idiomático y cultural de Alfonso el Sabio}

Util en extremo y del todo importante ha sido la labor de Alfonso X el Sabio en el campo idiomático y en el cultural:

\section{1) Legado idiomático}

- Don Alfonso sustituyó el latîn por el romance castellano en el momento en que el primero perdía vigencia.

- Como contraparte, le da impulso al segundo para universalizarlo.

- En los documentos reales, impulsó la prosa castellana y le confirió a éste un carácter oficial.

- Puso todo su empeño para que los documentos redactados en su "scriptorium" empleasen una lengua "correcta" y exacta.

- Seleccionó con buen criterio textos y los hizo "trasladar de aráuigo en lenguaie castellano porque los omne lo entendiesen meior et se sopiessen dél más aprovechar".

- Inicia la exposición histórica en romance con un sentido de unidad y de organización, con lo cual el castellano adquiere calidad y rango. 
- Asunto de mucha monta, en la Crónica General se prosifican, con propósitos históricos, los cantares de gesta; de este modo se pudo reconstruir, en lo esencial, los pasajes perdidos del Cantar del Mío Cid.

\section{2) Legado cultural}

- La tolerancia ideológica de Alfonso X el Sabio lo hace aceptar otras culturas, razas, religiones $y$ lenguas.

- Se constituye en un intermediario cultural entre la cultura greco-latina-románica y la árabe-judía.

- Su "scriptorium" se convierte en un centro de cultura universal, pues en él trabajan en paz judíos (Jehuda ben Moses), moros (Rabisag), cristianos españoles (Gil de Zamora), italianos (Buenaventura de Siena), provenzales (Paulet de Marsella).

- Su labor es enciclopédica: historia, jurisprudencia, astronomía, poesía, música, pintura.

- Reunió y sistematizó, en modo fiel, gran parte de la ciencia de su tiempo.

- Miras españolas en sus actuaciones, lo cual está demostrado por esta prosa: "Apartóse otro día con los de Aragón et portogaleses et gallegos et asturianos, esos que alli vinieron, et dijoles así el rey don Alfonso: "Amigos, todos nos somos españoles".

XX. Apéndice: algunas citas en apoyo de la labor idiomática de Alfonso $X$ el Sabio

1) Bernardo Aldrete (1606): "El Señor Rei Don Alfonso el decimo fue el primero, que honrro el Romance, porque como tan sabio principe reconocido, que los prudentes $i$ bien entendidos Emperadores tuuieron porpunto sustancial en materia de gouierno no admitir en las escrituras, i juzgados otro lenguaje, que el propio, $i$ assi lo ordeno, i mando"."

2) Gil Zamọra (1884): ..."quod omnes fere scripturas triviales et quadriviales, canonicas et civiles, scripturas quoque theologicas seu divinas transferri fecit in linguam maternam" (19).

3) Spaulding (1948): "The great stabilizer of the early Spanish language, (who) introduced or at least popularized a quantity of Latin and Arabic words" (20).

4) Galán (1954): "Alfonso creó la prosa didáctica".

5) Anderson: "Father of the Castilian prose".

6) D'Arrigo: "Durante il regno di Alfonso $X$,e grazie alla sua intensa attività scientifica e letteraria, il castigliano acquista dignità di lingua" (21).

7) Entwistle: "The care taken by Alfonso $X$ with the style of his works, ...was of the profoundest importance for the Spanish language". (22)

8) Niederehe: "...ohne den König keine dieser wertvollen Schriften entstanden und die Geschichte der spanischen Sprache anders verlaufen wäre" (23).

9) Américo Castro (citado por Niederehe): "Das Einwirken Alfons des Weisen auf seine Sprache kann daher gar nichts als Veränderung, sondern nur als Anwendung sprachlicher Regelns beschrieben"...(24).

10) Rafael Lapesa:..." "La consecuencia fue la creación de la prosa castellana"...; "fijación interna de la lengua a lo largo del reinado de Alfonso X"... "La labor de Alfonso X capacitó al idioma para la exposición didáctica"...; "la prosa castellana quedaba definitivamente creada"...(25).

11) Breve resumen Se aprecia en todas las citas anteriores un justo encomio por la labor idiomática de Alfonso X, quien, con todo derecho, lleva el sobrenombre de SABIO.

\section{NOTAS Y CITAS BIBLIOGRAFICAS}

1) Cita extraída de Hans-Josef Niederehe, Die Sprachauffassung Alfons des Weisen, pág. 16, quien, a su vez, cita a Solalinde, 5 edic. 1965,180 . (Alfonso mismo explica la palabra soueiana, así: "quando se dice además, 6 sobre cosas que non convengan á la natura del fecho sobre que se deben decir".

2) Cita de Rafael Lapesa, Historia de la lengua española. pág. 241.
3) Cita de Rafael Lapesa, op. cit., pág. 241.

4) Hans-Josef Niederehe, op. cit., pág. 99.

5) Hans-Josef Niederehe, op. cit., pág. 99.

6) Hans-Josef Niederehe, op. cit., pág. 100.

7) Hans-Josef Niederehe, op. cit., pág. 100. 
8) Gil de Zamora (1184.321), citado por Hans-Josef Niederehe, pág. 97.

9) Hans-Josef Niederehen, op. cit., pág. 89.

10) Traducción del autor: "Vosotros me parecéis franceses en el romance... este libro está escrito en el romance de Francia".

11) En francés "Amour Courtois".

112) Hans-Josef Niederehe, op. cit., pág. 84

13) Hans-Josef Niederehe, op. cit., pág. 84, nota 4.

14) Topónimos extraídos de Hans-Josef Niederehe, op. cit., pág. 180.

15) Hans-Josef Niederehe, op. cit., pág. 167.

16) Hans-Josef Niederehe, op. cit., págs. 109 y110.

17) Traducción del autor: "Gramática es la ciencia de hablar rectamente, $y$ el origen y fundamento de las artes liberales".

18) Texto extraído de Valbuena Prat, Historia de la literatura española, Vol. lo., págs. 121 y 122.

19) Traducción del autor:... "pues hizo traducir a su lengua materna casi todas las obras del Trivium $y$ del Quadrivium, del derecho canónico y del civil, así como asuntos teológicos o divinos".

20) Traducción del autor: "Gran estabilizador del español antiguo, quien introdujo, o al menos popularizó, una gran cantidad de palabras latinas y árabes".

21) Traducción del autor: "Durante el reinado del Alfonso $X$, gracias a su intensa actividad cient ífica $y$ literaria, el castellano adquiere la dignidad de lengua".

22) Traducción del autor: "El cuidado tenido por Alfonso $X$ con el estilo de sus obras, ...fue de la mayor importancia para la lengua española".

23) Traducción del autor: ..."sin el concurso del Rey no se hubiera originado ninguno de estos valiosos textos y la historia de la lengua española hubiera sido otra".

24) Traducción del autor: "Por ende, ta influencia de Alfonso el Sabio sobre la lengua no puede del todo ser definida no sólo como un cambio, sino también como un ejemplo de las reglas lingüísticas"...

25) Rafael Lapesa, op. cit., pág.

\section{BIBLIOGRAFIA}

Alborg, Juan Luis. Historia de la literatura españoIa, Editorial Gredos, Madrid, T. I., 1966.

Amado, Alonso. Castellano, español, idioma nacional (historia espiritual de tres nombres) Editorial Losada, Buenos Aires, 1979.

Anderson, Robert R. Alfonso $X$ el Sabio and the renaissance in Spain, in HISPANIA 44, págs. 448-453, 1961.

Bleiberg, German y Marías Julián. Diccionario de literatura española. Revista de Occidente, Madrid, 1964.

Diez-Echarri/Roca Franquesa. Historia general de la literatura española e hispanoamericana, Editorial Aguilar, Madrid, 1972.

Elcock, W. D. The romance languages, Faber and Faber, London, 1960.

García López, José. Historia de la literatura española, Editorial Vicens Vives, Barcelona, 1966.
Lapesa, Rafael. Historia de la lengua española, Editorial Gredos, Madrid, 1982.

Lázaro Carreter, Fernando. Lengua española: historia, teoría y práctica, I., ANAYA (Manuales de orientación universitaria), 1972.

Marcos. Marin, Francisco. Literatura castellana medieval (De las Jarchas a Alfonso X), Cuadernos de estudio. Serie: Literatura, Editorial Cincel, Madrid, 1982.

Menéndez Pidal, Gonzalo. "Como trabajaron las escuelas alfonsíes" en Nueva revista de filología hispánica, V, 1951.

Niederehe, Hans-Josef. Die Sprachauffasung A/fons des Weisen, Beihefte zur Zeitschrift für romanische Philologie, Band 144, Max Niemeyer Verlag, Tübingen, 1975.

Pedro Peira, Jesus Moreno. Crestomatía románica medieval, Ediciones CATEDRA, Madrid, 1979. 


\section{REVISTA DE FILOLOGIA Y LINGUISTICA}

Quirós Rodríguez, Manuel Antonio. "Castilla y el castellano; origen de un lugar, un idioma y un nombre", Revista de Filología y Lingüística de la Universidad de Costa Rica: VI (1 y 2), 1980.
Sainz de Robles, F. C. Diccionario de la literatura, Editorial Aguilar, Madrid.

Valbuena Prat, Angel. Historia de la literatura espoñola, Editorial Gustavo Gili, Barcelona, 1964. 